\title{
Prevalence of allergic diseases in children with inflammatory bowel disease
}

\author{
Zuzanna Wasielewska ${ }^{1}$, Aleksandra Dolińska', Dominika Wilczyńska', Anna Szaflarska-Popławska², Aneta Krogulska ${ }^{1}$ \\ ${ }^{1}$ Department of Paediatrics, Allergology and Gastroenterology, Ludwik Rydygier Collegium Medicum in Bydgoszcz, Nicolaus Copernicus \\ University in Torun, Poland \\ ${ }^{2}$ Department of Paediatric Endoscopy and Gastrointestinal Function Testing, Collegium Medicum in Bydgoszcz, Nicolaus Copernicus \\ University in Torun, Poland \\ Adv Dermatol Allergol 2019; XXXVI (3): 286-294 \\ DOI: https://doi.org/10.5114/ada.2018.81189
}

\begin{abstract}
Introduction: There are many similarities between inflammatory bowel disease (IBD) and allergic diseases, including similar epidemiological data, pathomechanism, clinical course and even treatment methods. So far, many studies of IBD comorbidity with other diseases, including allergy, but mainly in adults, have been conducted.

Aim: To analyse the prevalence of allergic diseases, i.e. food allergy (FA), cow's milk allergy (CMA), atopic dermatitis $(A D)$, allergic rhinitis (AR) and asthma in children with IBD.

Material and methods: The study included 105 IBD patients from the Department of Paediatrics, Allergology and Gastroenterology of Collegium Medicum in Bydgoszcz and 100 children without IBD from the Outpatient Clinics. The authors applied the validated questionnaire as a study method.

Results: At least one allergic disease was found in 26 (43\%) IBD children. The allergological diagnosis was made in IBD children more frequently than in the control group $(p=0.04)$. The difference was more noticeable with regards to skin prick tests $(p=0.02)$. FA was the most common disease; it was noted in $19(32 \%)$ IBD children; followed by: $A D$ - in 13 (22\%), CMA - in $12(20 \%), A R$ - in $10(17 \%)$ and asthma - in $6(10 \%)$ children. The prevalence of allergic diseases in the control and study groups was comparable $(p>0.05)$. There was no correlation between age of IBD children and allergy $(p>0.05)$. Asthma was significantly more common in children undergoing biological treatment $(p=0.01)$

Conclusions: Children with IBD should be constantly monitored by medical professionals, not only due to the underlying disease but also due to a possible concomitant allergic disease.
\end{abstract}

Key words: inflammatory bowel disease, allergy, children.

\section{Introduction}

A relationship between autoimmune diseases, such as inflammatory bowel disease (IBD) and allergic diseases has for long remained in the focus of attention. The diseases are similar to each other with regards to many aspects, including epidemiological and demographic data; pathomechanism, clinical course and even treatment methods are also similar [1, 2].

Inflammatory bowel diseases constitute a group of diseases which include Crohn's disease (CD) and ulcerative colitis (UC). Other cases, impossible to diagnose, are considered unspecified forms [3].
Inflammatory bowel diseases are believed to result from excessive immune response within the digestive system. They are also known to be connected with various extraintestinal manifestations, including the respiratory system, typical of allergic diseases [4-7].

Inflammatory bowel disease affects about 1.5 million Americans and about 2 million Europeans [1, 8, 9].

Prevalence of the disease in children is different. Most current epidemiological studies indicate that IBDs are diagnosed more often in children from West European countries $[8,10]$. Simultaneously, their prevalence is growing both in developed and in developing countries $[10,11]$. Recent studies, conducted in Asia, have revealed

Address for correspondence: Zuzanna Wasielewska, Department of Paediatrics, Allergology and Gastroenterology, Ludwik Rydygier Collegium Medicum, Nicolaus Copernicus University, 9 M. Skłodowskiej-Curie St, 85-094 Bydgoszcz, Poland, phone: +48 525854850 , fax: +48 5258540 86, e-mail: klped@cm.umk.pl, zkieraszewicz@gmail.com

Received: 30.11.2017, accepted: 17.03.2018. 
an increase in incidence and morbidity of IBD also in this continent, which might imply that this disease is a global problem [12].

Studies, carried out on children in Finland, showed that the prevalence of IBD increased from 7 per 100,000 population in 1987-1990 to 23 per 100,000 population in 2011-2014, i.e. on average, by 4\% [11]. Henderson et al. also noted that the disease is diagnosed at younger age; in 1990-1995, it was diagnosed in children aged 12.7 years old but between 2003 and 2008, the disease was detected already at the age of 11.9 years [13]. Similar results were obtained in Spain, Slovenia and Poland [14-16].

Allergic diseases, similarly to IBD, affect millions of people worldwide; they develop as early as in infancy and are characterized by remission and exacerbation periods. Besides, their prevalence is on the increase in both developed and developing countries [17-20]. Similarly to IBD, allergic diseases can manifest with digestive symptoms. Moreover, peri-delivery and environmental factors may also increase predisposition to IBD as well as to allergy $[8,16,21,22]$.

Pathomechanisms underlying both the diseases also contain a lot of similarities. The mechanism of their development still has not been clearly explained. However, disturbed balance between the immune system and gut microbiota in genetically predisposed individuals seem to be a key factor $[8,21,23]$. It was confirmed that in children with predisposed genotypes, changes in gut microbiota may lead to the development of immune disturbances, including atopic diseases and IBD [24-26]. Microbiota stimulates and "teaches" the immune system. Its composition depends on many factors. It was revealed that the more complex its composition is, the lower the risk of allergy and IBD is [27-30].

Apart from microbiota, also the epithelium plays an important role in the development of the above diseases. It is known that integrated cooperation of mucosal tissues, cells and effector molecules of, the respiratory tract, digestive tract and female genital tract etc., makes up an effective protection against environmental factors and pathogens. A defect in the mucosal barrier, or the epithelium, is responsible for an increase in the number of diseases of the digestive system (IBD, irritable bowel syndrome - IBS) and the respiratory system (allergic rhinitis - AR, asthma, chronic obstructive pulmonary disease-COPD) [31].

Walker et al. believe that the complex pathomechanism, underlying IBD and atopic disturbances, can be explained by immune disturbances, involving e.g. eosinophils, T helper cells - Th-2 and Th-17 and transforming growth factor $\beta$ (TGF- $\beta$ ) [32-35]. It was also confirmed that tumor necrosis factor $\alpha$ (TNF- $\alpha$ ) cytokine plays an important role in the pathogenesis of CD. The sources of the cytokine are monocytes, macrophages and mast cells (mastocytes), found in intestinal walls of CD patients [36, 37]. We should also point out that mast cells and TNF- $\alpha$ cytokine substantially contribute to the pathomechanism of atopic diseases such as asthma, AR or atopic dermatitis (AD) $[25,38]$.

Another element, typical for both IBD and allergy, is the clinical course, during which not only the digestive system but also the respiratory one and the skin are affected. Clinical manifestations of IBD and food allergy (FA) include abdominal pain, diarrhoea (occasionally with mucous and blood discharge), general weakness, malaise, symptoms of malabsorption (weight loss, inhibition of body weight gain and growth in children, anaemia etc.). Skin lesions and respiratory symptoms, which are typical for allergic diseases, occur also in the course of IBD. However, they are much less frequent [39].

Due to common pathomechanisms, similar therapies are applied in both the diseases. The treatment includes administration of immunomodulators and immunosuppressants, such as steroids, cyclosporine. Besides, biological drugs are also applied. A diet is another important factor. Clinical nutrition is used both in allergy and CD. In other forms of allergy and IBD, a diet may be only a potential and additional element of an implemented therapy. However, the role of a diet is still a subject of scientific research. Besides, there is hope that probiotics will soon appear to be beneficial in the treatment of IBD and allergic diseases [2, 40, 41].

\section{Aim}

So far, many studies on concomitant IBDs and other diseases, including allergic diseases, but mainly in adult patients, have been conducted. The aim of the presented study is to analyse prevalence of allergic diseases, i.e. FA, cow's milk allergy (CMA), AD, AR and asthma in children with IBD.

\section{Material and methods}

The study included 105 IBD patients, i.e. all patients treated in the Department of Paediatrics, Allergology and Gastroenterology of Collegium Medicum in Bydgoszcz and the Outpatient Gastroenterology Clinic, between 1 January 2015 and 30 June 2016. IBD was diagnosed on the basis of clinical, endoscopic, histopathological and radiological criteria, according to guidelines of the European Society for Paediatrics, Gastroenterology, Hepatology, and Nutrition (ESPGHAN) [3].

The authors applied their own validated questionnaire as a study method. Depending on paediatric patients' parents, the questionnaire was sent via mail, e-mail, or the parents were asked to fill it in during their children's hospitalization in the department. One hundred children without IBD from the Primary Health Care Outpatient Clinic from Bydgoszcz made up the control group. The questionnaire consisted of 12 questions on occurrence of allergic diseases in the studied children. By reducing the number of questions, the authors wanted to receive the largest possible feedback. Allergy 


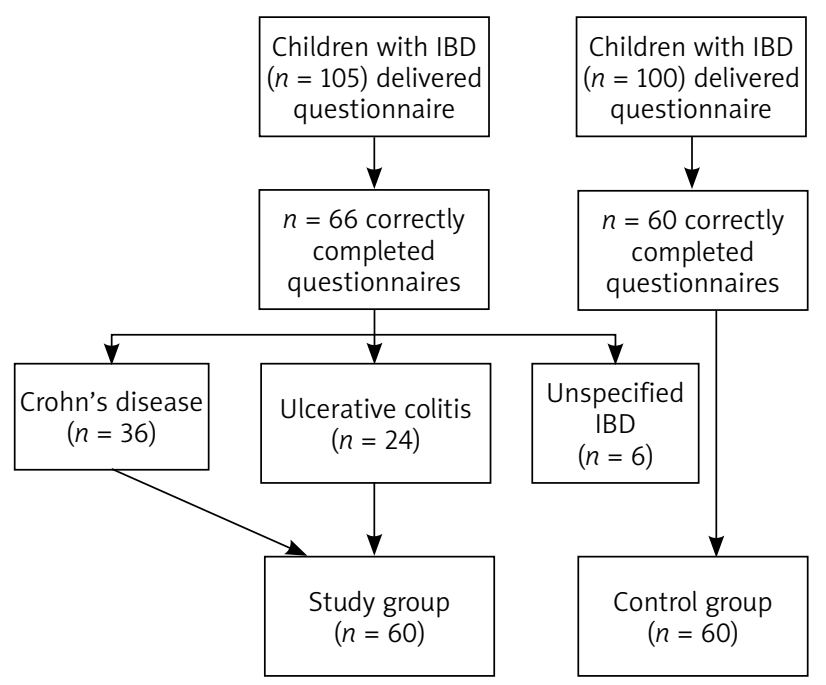

Figure 1. Scheme of the study

symptoms, given in the questionnaire, were compliant with guidelines of scientific associations, such as Global INitiative for Allergy (GINA) [42], Allergic Rhinitis and its Impact on Asthma (ARIA) [43], and European Academy of Allergy and Clinical Immunology (EAACI) [44]. The study had a form of a questionnaire with open-ended, closed-ended or/and halfopen questions. Due to the fact that the study had a form of a questionnaire, the patients were asked to answer questions some of which referred to the same topic. The authors applied this method to verify answers and ensure the most reliable possible data. A questionnaire was partially adopted with the authors' own modification from the ISAAC study [45].

Finally 60 children with IBD and 60 healthy children were included in the study. Figure 1 presents the scheme of the study.

According to the Paris classification, the study children were divided into three age groups: $<10$ years old, 10-17 years old and $\geq 17$ years old [46]. In an analysis of the clinical course of the disease, implementation of biological therapy (infliximab or adalimumab) was identi- fied with the degree of disease severity: severe course biological treatment, mild/moderate course - not implementing such therapy.

Table 1 presents characteristics of the study and control groups at the time of data collection. The mean age of diagnosing CD was $12.04 \pm 3.42$ years (median 12 years). With regards to UC, it was $10.60 \pm 4.27$ years (median - 11 years).

In 15 (25\%) children with IBD, the disease was diagnosed below the age of 10 years; in $5(8 \%)$ - at the age of 17 or later. In the rest of the children, i.e. in 40 (67\%), IBD was diagnosed between the age of 10 and 17 years. In the study group, 22 (37\%) children were administered biological treatment.

\section{Statistical analysis}

For quantitative data, results were analysed with the use of the following parameters: number of cases $(N)$, mean value (M), standard deviation (SD), minimum (Min.), maximum (Max.) and median (Me). For qualitative (categorized) variables, results were analysed by comparing the relative number of cases $(\mathrm{N})$ and their percentage in the study group. The authors applied the $U$ Mann-Whitney test in order to find any different values of particular quantitative factors in the studied groups, and odds ratio with confidence intervals for the distribution of categorized variables. In order to identify factors which are important for the occurrence of $U C$ and $C D$, a logistic regression analysis (stepwise, forward) was used. Odds ratio for unit change of the used parameters and odds ratio for a change equal to the range of the analysed variables were calculated with 95\% confidence intervals. In all analysed parameters, $p<0.05$ was considered statistically significant. The computer programme Statistica 13.1 (Statsoft, Cracow, Poland) was used for the purpose of the statistical analysis.

\section{Results}

An analysis of questionnaire results revealed that an allergological diagnosis was made in 38 (63\%) patients.

Table 1. Characteristics of the study and control groups at the time of data collection

\begin{tabular}{|c|c|c|c|c|c|}
\hline \multirow[t]{2}{*}{ Data } & \multicolumn{3}{|c|}{$\begin{array}{l}\text { Study group } \\
N=60(100 \%)\end{array}$} & \multirow[t]{2}{*}{$\begin{array}{l}\text { Control group } \\
n=60(100 \%)\end{array}$} & \multirow[t]{2}{*}{$P$-value } \\
\hline & $\begin{array}{c}C D \\
n=36(100 \%)\end{array}$ & $\begin{array}{c}\text { UC } \\
n=24(100 \%)\end{array}$ & $\begin{array}{c}\text { Summary } \\
n=60(100 \%)\end{array}$ & & \\
\hline Age [years]: & & & & & 0.231 \\
\hline Average \pm SD & $15.0 \pm 3.08$ & $14.3 \pm 3.89$ & $14.72 \pm 3.41$ & $14.85 \pm 2.92$ & \\
\hline Median & 15.38 & 14.71 & 15.16 & 14.0 & \\
\hline Min.-max. & $4.75-18.5$ & $6.08-19.25$ & $4.75-19.25$ & $6.58-18.71$ & \\
\hline Sex, $n(\%):$ & & & & & 0.144 \\
\hline Boys & $21(58)$ & $14(58)$ & $35(58)$ & $26(43)$ & \\
\hline Girls & $15(42)$ & $10(42)$ & $25(42)$ & $34(57)$ & \\
\hline
\end{tabular}


Of this number, 17 (71\%) children were diagnosed with UC and 21 (58\%) - with CD. The most common diagnostic method was a skin prick test (SPT). It was applied in 33 (55\%) children (15; 63\% with UC and 18 ; 50\% with CD). Next, serum specific IgE level was determined in 14 (23\%) children (8; $33 \%$ with UC and $6 ; 17 \%$ with CD); in $7(12 \%)$ children $(5 ; 21 \%$ with UC and $2 ; 6 \%$ with CD), the authors applied atopy patch tests (APTs). In the control group, an allergological diagnosis was made in 26 (43\%) children and it included SPTs in 21 (35\%) children, serum specific IgE determination in 12 (20\%) children and APTs in $3(5 \%)$ children. It was revealed that an allergological diagnosis was made in children with IBD statistically more frequently than in children from the control group $(p=0.044)$. The difference was more noticeable with regards to SPTs $(p=0.027)$.

Of 60 children from the study group, 26 (43\%) demonstrated sensitization to the following allergens. They mostly included mites - 16 (27\%) children, grass - 12 (20\%) children, moulds -7 (12\%) children and foods (no particular allergen was given) - 5 (8\%) children. Allergy to grains and animal fur was observed in 4 (7\%) children. Less frequently were the children allergic to artemisia or trees -2 (3\%) children were allergic to one plant and another 2 - to the other plants.

In the control group, sensitization to the allergens was observed in 9 (15\%) children and the allergens included foods (no particular allergen was given) - in $5(8 \%)$ children, trees in $4(7 \%)$ children; followed by mites - in $3(5 \%)$ children, moulds - in 2 (3\%) children, grass - in $2(3 \%)$ children and animal fur - in 1 (2\%) child.

Twenty (33\%) children from the study group and $6(10 \%)$ children from the control group $(p>0.05)$ demonstrated allergy to inhaled allergens. With regards to children with UC, inhaled allergy was observed in 8 (33\%) children, and FA - in 2 (8\%) children. In the group of CD patients, the respective values were: 12 (33\%) children and $3(8 \%)$ children $(p>0.05)$.
The prevalence of FA in the control and study group is presented in Table 2. Table 3 presents prevalence of FA in the study group depending on the sex, age at diagnosis and applied biological therapy.

A food product, which was responsible for clinical symptoms and, thus, most commonly eliminated from the diet of the studied children, was milk in - 14 (23\%) children and eggs - in 7 (12\%) children. Next, the following foods were eliminated: nuts - in 5 (8\%) children and peanuts - in $6(7 \%)$ children. Soya was excluded twice (3\%), and fish and wheat flour were eliminated once (2\%). In 5 (8\%) children, the authors could not identify a product which caused FA. In the control group, similarly to the study group, milk was eliminated most often - in $8(13 \%)$ children, next, nuts - in $2(3 \%)$ children. In single patients, the foods were: pork, broccolis, apples and potatoes. One patient was not able to identify the allergen.

The prevalence of CMA in infancy in the study and control groups was comparable (Table 2). No observed value (sex, age when IBD was diagnosed, applied biological therapy) was statistically significant (Table 3).

The AR occurred in 10 (17\%) children with IBD; of this number, 6 (17\%) children suffered from CD and 4 (17\%) - from UC (Table 2). AR was noted more often in boys (8; $23 \%)$ than in girls $(2 ; 8 \%)$ and most of the AR children (9; $23 \%)$ developed CD or UC when they were aged 10-17 years. Only 3 (14\%) AR children were administered a biological therapy (Table 3). In the control group, AR was observed insignificantly less frequently - 6 (10\%) children were affected by the disease $(p=0.561)$ (Table 2).

In the group of IBD children, who were not diagnosed with $A R$, seasonal watery rhinitis was observed in 18 (30\%) children; 17 (28\%) children demonstrated sneezing and nasal pruritus and 11 (18\%) of them - nasal blockage. Conjunctival symptoms, concomitant with rhinitis, were observed in 11 (18\%) children. Sixteen (27\%) children demonstrated at least two of the given symptoms.

The prevalence of asthma in the control and study groups is presented in Table 2 . A further analysis did not

Table 2. Risk of allergic diseases in children in the study and control groups

\begin{tabular}{|c|c|c|c|c|c|c|c|c|c|c|}
\hline $\begin{array}{l}\text { Type of } \\
\text { allergic } \\
\text { disease }\end{array}$ & $\begin{array}{c}\text { Children } \\
\text { with CD } \\
N=36 \\
(100 \%)\end{array}$ & $\begin{array}{c}\text { Children } \\
\text { with UC } \\
N=24 \\
(100 \%)\end{array}$ & $P$-value & $\begin{array}{c}\text { Children } \\
\text { with IBD } \\
N=60 \\
(100 \%)\end{array}$ & $\begin{array}{l}\text { Control } \\
\text { group } \\
N=60 \\
(100 \%)\end{array}$ & $P$-value & $\begin{array}{l}\text { OR }(95 \% \mathrm{Cl}) \\
\quad \text { for CD }\end{array}$ & $P$-value & $\begin{array}{l}\text { OR }(95 \% \mathrm{Cl}) \\
\text { for UC }\end{array}$ & $P$-value \\
\hline FA & 12 (33\%) & 7 (29\%) & 0.115 & 19 (32\%) & $12(20 \%)$ & 0.235 & $\begin{array}{c}2.000 \\
(0.786-5.111)\end{array}$ & 0.144 & $\begin{array}{c}1.647 \\
(0.557-4.869)\end{array}$ & 0.365 \\
\hline CMA & $9(25 \%)$ & $3(13 \%)$ & 0.235 & 12 (20\%) & 11 (18\%) & 0.235 & $\begin{array}{c}1.604 \\
(0.587-4.377)\end{array}$ & 0.354 & $\begin{array}{c}0.636 \\
(0.161-2.517)\end{array}$ & 0.385 \\
\hline$A R$ & $6(17 \%)$ & $4(17 \%)$ & 1.000 & 10 (17\%) & $6(10 \%)$ & 0.561 & $\begin{array}{c}1.480 \\
(0.494-4.435)\end{array}$ & 0.484 & $\begin{array}{c}1.400 \\
(0.408-4.800)\end{array}$ & 0.593 \\
\hline Asthma & 4 (11\%) & $2(8 \%)$ & 0.725 & $6(10 \%)$ & $4(7 \%)$ & 0.641 & $\begin{array}{c}0.493 \\
(0.153-1.584)\end{array}$ & 0.235 & $\begin{array}{c}0.3684 \\
(0.080-1.705)\end{array}$ & 0.202 \\
\hline$A D$ & $6(17 \%)$ & 7 (29\%) & 0.249 & 13 (22\%) & $8(13 \%)$ & 0.252 & $\begin{array}{c}0.920 \\
(0.325-2.601)\end{array}$ & 0.875 & $\begin{array}{c}2.412 \\
(0.847-6.871)\end{array}$ & 0.100 \\
\hline
\end{tabular}


Table 3. FA, CMA, asthma, $A R$ and $A D$ in the study group depending on the sex, age at diagnosis and applied biological therapy

\begin{tabular}{|c|c|c|c|c|c|c|c|c|c|c|}
\hline \multirow{2}{*}{$\begin{array}{l}\text { Type of } \\
\text { allergic } \\
\text { disease }\end{array}$} & \multicolumn{2}{|c|}{ Sex } & \multirow[t]{2}{*}{$P$-value } & \multicolumn{3}{|c|}{ Age at diagnosis } & \multirow[t]{2}{*}{$P$-value } & \multicolumn{2}{|c|}{ Biological therapy } & \multirow[t]{2}{*}{$P$-value } \\
\hline & $\begin{array}{l}\text { Boys } \\
N=35 \\
(100 \%)\end{array}$ & $\begin{array}{c}\text { Girls } \\
N=25 \\
(100 \%)\end{array}$ & & $\begin{array}{c}\leq 10 \text { y.o } \\
N=15 \\
(100 \%)\end{array}$ & $\begin{array}{c}10-17 \text { y.o. } \\
N=40 \\
(100 \%)\end{array}$ & $\begin{array}{c}>17 \text { y.o. } \\
N=5 \\
(100 \%)\end{array}$ & & $\begin{array}{c}\text { Yes } \\
N=22 \\
(100 \%)\end{array}$ & $\begin{array}{c}\text { No } \\
N=38 \\
(100 \%)\end{array}$ & \\
\hline FA & $15(43 \%)$ & $4(16 \%)$ & 0.087 & $5(33 \%)$ & $11(28 \%)$ & $3(60 \%)$ & 0.232 & $5(23 \%)$ & $14(37 \%)$ & 0.526 \\
\hline CMA & $9(26 \%)$ & $3(12 \%)$ & 0.190 & $2(13 \%)$ & $8(20 \%)$ & $2(40 \%)$ & 0.434 & $3(14 \%)$ & $9(24 \%)$ & 0.348 \\
\hline AR & $8(23 \%)$ & $2(8 \%)$ & 0.128 & $0(0 \%)$ & 9 (23\%) & $1(20 \%)$ & 0.133 & $3(14 \%)$ & $7(18 \%)$ & 0.632 \\
\hline Asthma & $4(11 \%)$ & $2(8 \%)$ & 0.662 & $2(13 \%)$ & $3(8 \%)$ & $1(20 \%)$ & 0.600 & $5(23 \%)$ & $1(3 \%)$ & 0.013 \\
\hline$A D$ & 10 (29\%) & $3(12 \%)$ & 0.124 & $4(27 \%)$ & 7 (18\%) & $2(40 \%)$ & 0.444 & $3(14 \%)$ & $10(26 \%)$ & 0.250 \\
\hline
\end{tabular}

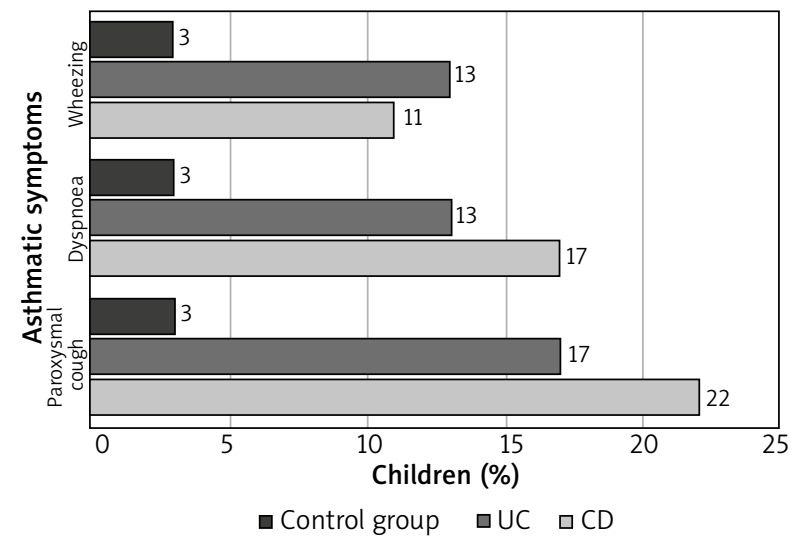

Figure 2. Asthmatic symptoms after exertion in children without asthma but with CD and UC, in comparison to the control group

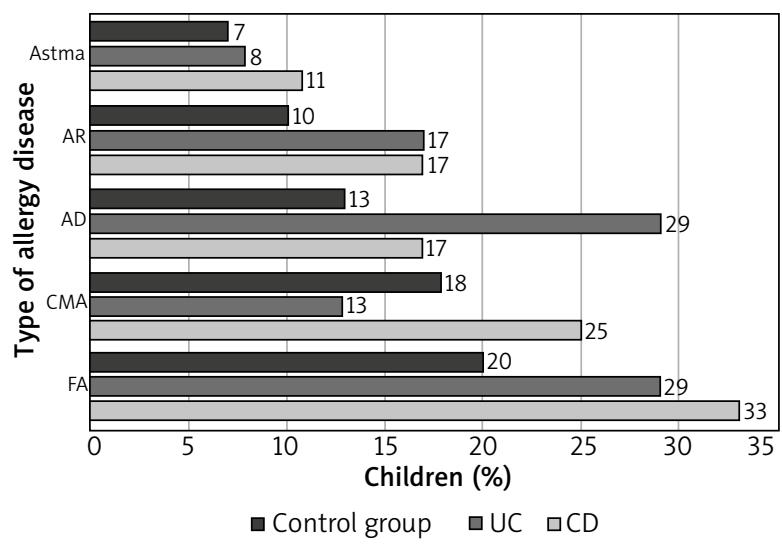

Figure 3. The prevalence of allergic diseases in children with IBD and children in the control group

confirm a relationship between the sex of patients and age when IBD was diagnosed and the prevalence of asthma in the study group. However, the authors noted that asthma occurred statistically more frequently in children with a severe course of IBD $(p=0.013)$ (Table 3). Figure 2 presents asthmatic symptoms after exertion in children without asthma but with CD and UC, in comparison to the control group.

The prevalence of AD in the control and study groups is presented in Table 2. However, the difference was insignificant. Besides, the authors noted a higher prevalence of $A D$ in boys than in girls with IBD. Similarly, there was no relationship between the prevalence of $A D$ in the studied children and the severity of IBD and the age when the disease was detected (Table 3).

With regards to the study group, FA was the most common disease; it was noted in 19 (32\%) children; followed by: AD - in 13 (22\%) children, CMA - in 12 (20\%) children, AR - in 10 (17\%) children. The least frequent disease was asthma, which was noted in $6(10 \%)$ children. At least one allergic disease was revealed in 26 IBD children (43\%). The prevalence of the above allergic diseases in the control and study groups was comparable ( $p>0.05$ ) (Figure 3).

A logistic regression analysis is shown in Table 2 . Similarly to CD children, also UC children demonstrated an increased, however insignificant, risk of FA and $A R$. Besides, the authors revealed an increased risk of $A D$ in UC children and an increased risk of CMA in CD children.

\section{Discussion}

The authors did not reveal significant differences with regards to the prevalence of allergic diseases, including FA, asthma, AR and AD in children with IBD in comparison to the control group; yet, CMA was observed two-fold more frequently in children with $C D$ than with UC. With regards to $A D$, it was observed two-fold more frequently in children with UC than in children with CD. Virta et al., having analysed study results in 595 Finnish IBD children and 2380 children from the control group, observed that childhood CMA occurred significantly more frequently in children with $C D$ and UC than in children without IBD [32]. In 1990, Glassman et al. published a study, which confirmed a far higher prevalence of childhood CMA in children with UC (20.9\%) and CD (8.5\%) 
than in the control group (2.8\%) [47]. Data regarding the prevalence of FA in IBD are different. Imanzadeh et al. conducted a study on 28 IBD children and noted FA in $60.7 \%$ of patients. $35.7 \%$ of the above patients demonstrated allergy to more than one food allergen. The most common allergen was cow's milk protein [48]. In the authors' own study, the corresponding parameters were lower and their values were $32 \%$ and $23 \%$, respectively. Similarly to other publications [49, 50], the authors of the study noted that the most common allergen, responsible for the occurrence of FA, was cow's milk protein.

Lack of significant relationships in the authors' own study may result from the small size of the study group and a high prevalence of FA in the control group, higher than in the population survey, called the Epidemiology of Allergic Diseases in Poland (ECAP), conducted in Poland in the years 2006-2008 [51].

Although asthma in IBD children was observed in the authors' own study more frequently than in the control group, the difference was not statistically significant. Virta et al. made similar observations. They noted a higher prevalence of asthma in children with IBD but the values were significant only in patients with CD $-11.6 \%$ (in the control group $-5.5 \%$ ) [32]. The authors of the study did not observe differences with regards to the prevalence of asthma between children with CD and children with UC. A questionnaire, conducted by Myrelid et al. on adult patients, confirmed a higher prevalence of asthma in patients with $\mathrm{IBD}$, than in the control group (15\% vs. $12 \%$ ); however, the difference was statistically insignificant [52]. Kuenzig et al., having analysed results obtained from 5,000 Canadian patients with IBD, noted that the prevalence of asthma was correlated with an increased risk (occurrence of incidents) of CD (regardless of when the disease was diagnosed) and UC (the disease diagnosed before the age of 17 years or after the age of 40 years) [53].

An analysis of the authors' study results reveals a statistically significant higher prevalence of asthma in IBD children who were administered anti-TNF preparations during the treatment period. A more severe course of IBD seems to be a factor which predisposes to a higher prevalence of asthma in such patients.

Considering available publications and results of the study conducted by the authors, it seems reasonable to provide IBD children with extra examinations of the respiratory system. Such additional examinations might facilitate early detection of respiratory diseases in these patients. Tzanakis et al. made similar suggestions. Having analysed the professional literature, including eight studies on concomitant diseases in adult IBD patients, they concluded that radiography and functional examinations of the respiratory system are advisable in such patients as their results might help to detect subclinical forms of respiratory diseases, which these patients are, far more than the rest of the population, threatened with [4]. This conclusion seems to be important also in the population of developmental age, particularly in the light of results obtained by the authors of this study since as many as 9 (15\%) non-asthmatic patients demonstrated at least two symptoms imitating asthma, which might imply certain underestimation of this disease in the studied patients.

Frequent concomitance of asthma and IBD may be caused by a similar structure of lymphatic tissue of mucous membranes of the bronchial tree and alimentary tract, which play a key role in protection against pathogenic and environmental factors. Kanazawa et al. analysed the level of the vascular endothelial growth factor (VEGF) in the sputum of UC patients and in controls with and without asthma. The VEGF level appeared to be higher in UC patients with bronchial asthma than in asthmatic patients but not affected by UC. The authors suppose that interactions between microcirculation in airways and VEGF are key factors for functional disturbances of the respiratory system in UC children with asthma [54].

Peng et al. conducted a cohort study on 5,260 patients with diagnosed CD or UC and evaluated the risk of allergic diseases in comparison to patients without IBD. IBD patients demonstrated a higher risk of asthma (7.04 in comparison to 4.50 per 1,000 man-years) [55].

Milligan et al. revealed that the prevalence of asthma in American children in developmental age is estimated to be $8-13 \%$ [17]. In the ECAP project, the prevalence of asthma was estimated to be around 11\% [51]. The prevalence of asthma in the control group from the authors' own study is similar to the above values.

The authors of the study noted that the prevalence of AR in the study group was $17 \%$, whereas in the control group, it was $10 \%$. The prevalence of AR in children with CD or UC was comparable. What seems interesting, is the fact that parents of almost $30 \%$ of IBD children claimed that their children demonstrated two or more symptoms, typical of AR, which might imply certain underestimation of this disease, as in the case of asthma.

There are few studies on the correlation of AR prevalence and IBD. Those available studies mainly refer to adults. Kappelman et al. observed higher concomitance of allergic diseases, including AR (but also asthma and $A D$ ) in a group of 1,225 children with UC and CD, in comparison with the control group. However, the relationship was not statistically significant [56]. In a systematic review, regarding the prevalence of atopic diseases in adults with IBD, the authors quote two studies, in which they observed a higher prevalence of AR - respectively in $18 \%$ of CD patients and in $12 \%$ of UC patients vs. $6 \%$ in the control group and in $19 \%$ of IBD patients vs. $11 \%$ from the control group $[33,57,58]$. Results obtained by the authors of this study are similar to those obtained by Roberts et al. Peng et al., mentioned previously, made a similar observation (13\% in IBD patients vs. $8 \%$ in the control group) [55]. However, not all studies reveal a high- 
er prevalence of AR in the course of IBD. Myrelid et al. did not confirm such an observation and claimed that AR occurred in $20 \%$ of patients with IBD vs. in $19 \%$ from the control group [52].

In Poland, AR is the most common manifestation of allergic diseases and it affects $24 \%$ of children aged 6-7 years old and $30 \%$ of children aged 13-14 years old [51]. Keil et al. noted AR in $6 \%$ of children under the age of 3 and in 24\% of children aged 13 years [59]. Thus, AR prevalence, observed in the authors' own study is lower than in the above mentioned studies, which might be associated with the small size of the group and underestimation of the prevalence of the disease.

In the presented study, AD was the most common allergic disease, reported by the patients' parents. It was observed in above $20 \%$ of children with IBD and in about $10 \%$ of children from the control group. Results obtained by the authors of this study correspond to results obtained by Myrelid et al., who revealed that the prevalence of $A D$ was almost two-fold higher in patients with $C D$ in comparison to the control group [52]. A similar prevalence tendency was observed by Peng et al., who conducted a study on an adult population and confirmed a higher prevalence of $A D$ in patients with IBD than in the control group (1.5\% vs. 0.8\%) [55].

Data on the prevalence of $A D$ are different and the values range between $15 \%$ and $20 \%$ in children and $1 \%$ and $3 \%$ in adults. Results of an epidemiological study, conducted in Poland, indicated that AD affects on average $9 \%$ of children [51]; these data are comparable to the ones obtained by the authors of this study.

It should be stressed that the study group included children who demonstrated symptoms imitating an allergic disease but they had not been diagnosed by then.

Despite the occurrence of many similarities between allergic diseases and IBD with regards to the clinical course, pathomechanism, epidemiology, children with IBD did not appear to demonstrate allergic diseases significantly more frequently than children from the control group. Weaknesses of the study are a limited database of children with IBD and the method of gathering data, i.e. a retrospective analysis, made on the basis of information obtained during an anamnesis. A simple and short questionnaire is easy to conduct but on the other hand, it increases the risk of giving wrong answers. The conducted study is the first one of that kind ever carried out in Poland. It can be treated as an introduction to a further and more detailed evaluation of analysed issues.

\section{Conclusions}

No statistically significant difference was observed with regards to the prevalence of allergic diseases between IBD children and children from the control group. FA was the most common allergic disease, concomitant in children with IBD. FA was followed by AD, CMA and AR.
Asthma occurred least frequently. Study results indicate possible underestimation of the prevalence of allergic diseases in children with IBD. Children with IBD should be constantly monitored by medical professionals, not only due to the underlying disease but also due to a possible concomitant allergic disease. Further studies on concomitant allergic diseases in IBD paediatric patients should be continued.

\section{Conflict of interest}

The authors declare no conflict of interest.

\section{References}

1. Stawarski A, Iwańczak F, Iwańczak B, et al. Analiza obrazu klinicznego choroby Leśniowskiego-Crohna u dzieci. Pediatr Pol 2000; 75: 283-90.

2. Sischerer S, Sampson H. Food allergy: epidemiology, pathogenesis, diagnosis, and treatment. J Allergy Clin Immunol 2014; 133: 291-307.

3. Levine A, Koletzko S, Turner D, et al. ESPGHAN Revised Porto Criteria for the diagnosis of inflammatory bowel disease in children and adolescents. J Pediatr Gastroenterol Nutr 2014; 58: 795-806.

4. Tzanakis N, Tsiligianni I, Siafakas N. Pulmonary involvement and allergic disorders in inflammatory bowel disease. World J Gastroenterol 2010; 16: 299-305.

5. Rothfuss K, Stange E, Herrlinger K. Extraintestinal manifestations and complications in inflammatory bowel diseases. World I Gastroenterol 2006; 12: 4819-31.

6. Papanikolaou I, Kagouridis K, Papiris S. Patterns of airway involvement in inflammatory bowel diseases. World I Gastrointest Pathophysiol 2014; 5: 560-9.

7. Black H, Mendoza M, Murin S. Thoracic manifestations of inflammatory bowel disease. Chest 2007; 131: 524-32.

8. Gearry R, Richardson A, Frampton C, et al. Population-based cases control study of inflammatory bowel disease risk factors. J Gastroenterol Hepatol 2010; 25: 325-33.

9. Ananthakrishnan A. Epidemiology and risk factors for IBD. Nat Rev Gastroenterol Hepatol 2015; 12: 205-17.

10. Benchimol E, Fortinsky K, Gozdyra P, et al. Epidemiology of pediatric inflammatory bowel disease: a systematic review of international trends. Inflamm Bowel Dis 2011; 17: 423-39.

11. Virta L, Saarinen M, Kolho K. Inflammatory bowel disease incidence is on the continuous rise among all paediatric patients except for the very young: a nationwide registrybased study on 28-year follow-up. J Crohns Colitis 2017; 11: 150-6.

12. Chuang C, Lin S, Chen C, et al. Increasing incidence and lifetime risk of inflammatory bowel disease in Taiwan: a nationwide study in a low-endemic area 1998-2010. Inflamm Bowel Dis 2013; 19: 2815-9.

13. Henderson P, Hansen R, Cameron F, et al. Rising incidence of pediatric inflammatory bowel disease in Scotland. Inflamm Bowel Dis 2012; 18: 999-1005.

14. Martín-de-Carpi J, Rodríguez A, Ramos E, et al. Increasing incidence of pediatric inflammatory bowel disease in Spain (1996-2009): the SPIRIT Registry. Inflamm Bowel Dis 2013; 19: 73-80.

15. Urlep D, Blagus R, Orel R. Incidence trends and geographical variability of pediatric inflammatory bowel disease in Slovenia: a nationwide study. Biomed Res Int 2015; 2015: 921730. 
16. Karolewska-Bochenek K, Lazowska-Przeorek I, Albrecht P, et al. Epidemiology of inflammatory bowel disease among children in Poland. Digestion 2009; 79: 121-9.

17. Milligan K, Matsui E, Sharma H. Asthma in urban children: epidemiology, environmental risk factors, and the public health domain. Curr Allergy Asthma Rep 2016; 16: 33.

18. Nutten S. Atopic dermatitis: global epidemiology and risk factors. Ann Nutr Metab 2015; 66: 8-16.

19. Wood R. Advances in food allergy in 2015. J Allergy Clin Immunol 2016; 138: 1541-7.

20. Genuneit J, Seibold A, Apfelbacher C, et al. Overview of systematic reviews in allergy epidemiology. Allergy 2017; 72 : 849-56.

21. Dixon L, Kabi A, Nickerson K, et al. Combinatorial effects of diet and genetics in inflammatory bowel disease pathogenesis. Inflamm Bowel Dis 2015; 21: 912-22.

22. Sardecka I, Krogulska A, Toporowska-Kowalska E. The influence of dietary immunomodulatory factors on development of food allergy in children. Adv Dermatol Allergol 2017; 34: 89-96.

23. Guo A, Stevens B, Wilson R, et al. Early life environment and natural history of inflammatory bowel diseases. BMC Gastroenetrology 2014; 14: 216.

24. Gensollen T, lyer S, Kasper D, et al. How colonization by microbiota in early life shapes the immune system. Science 2016; 352: 539-44.

25. Garn H, Bahn S, Baune B, et al. Current concepts in chronic inflammatory diseases: interaction between microbes, cellular metabolism, and inflammation. J Allergy Clin Immunolol 2016; 138: 47-56.

26. Li M, Wang M, Donovan S. Early development of the gut microbiome and immune-mediated childhood disorders. Semin Reprod Med 2014; 32: 74-86.

27. Prince B, Mandel M, Nadeau K. Gut microbiome and the de velopment of food allergy and allergic disease. Pediatr Clin North Am 2015; 62: 1479-92.

28. Fujimura K, Lynch S. Microbiota in allergy and asthma and the emerging relationship with the gut microbiome. Cell Host Microbe 2015; 17: 592-602.

29. Matsuoka K, Kanai T. The gut microbiota and inflammatory bowel disease. Semin Immunopathol 2015; 37: 47-55.

30. Becker C, Neurath M, Wirtz S. The intestinal microbiota in inflammatory bowel disease. ILAR J 2015; 56: 192-204.

31. Tulic M, Piche T, Verhasselt V. Lung-gut cross-talk: evidence, mechanisms and implications for the mucosal inflammatory diseases. Clin Exp Allergy 2016; 46: 519-28.

32. Virta L, Ashorn M, Kolho K. Cow's milk allergy, asthma, and pediatric IBD. J Pediatr Gastroenterol Nutr 2013; 56: 649-51.

33. Walker M, Powell N, Talley N. Atopy and the gastrointestinal tract-a review of a common association in unexplained gastrointestinal disease. Expert Rev Gastroenterol Hepatol 2014; 8: 289-99.

34. Kotlyar D, Shum M, Hsieh J, et al. Non-pulmonary allergic diseases and inflammatory bowel disease: a qualitative review. World J Gastroenterol 2014; 20: 11023-32.

35. Hemdan N, Birkenmeier G, Wichmann G, et al. Interleukin17-producing $T$ helper cells in autoimmunity. Autoimmun Rev 2010; 9: 785-92

36. Bischoff S, Lorentz A, Schwengberg S, et al. Mast cells are an important cellular source of tumour necrosis factor alpha in human intestinal tissue. Gut 1999; 44: 643-52.
37. Lilja I, Gustafson-Svärd C, Franzén L, et al. Tumor necrosis factor-alpha in ileal mast cells in patients with Crohn's disease. Digestion 2000; 61: 68-76.

38. Leung D, Atopic dermatitis: the skin as a window into the pathogenesis of chronic allergic diseases. J Allergy Clin Immunol 1995; 96: 302-18.

39. Kacprzak A, Szturmowicz M, Kuś J. Respiratory system involvement in inflammatory bowel diseases. Adv Respir Med 2017; 85: 161-8.

40. Turner D, Levine A, Escher J, et al. Management of pediatric ulcerative colitis: joint ECCO and ESPGHAN evidence-based consensus guidelines. J Pediatr Gastroenterol Nutr 2012; 55 : 340-61.

41. Ruemmele F, Veres G, Kolho K, et al. Consensus guidelines of ECCO/ESPGHAN on the medical management of pediatric Crohn's disease. J Crohns Colitis 2014; 8: 1179-207.

42. Global Initiative for Asthma (GINA): Global Strategy for Asthma Management and Prevention. Updated 2015. WHO/ NHLBI Workshop Report 2015.

43. Bousquet J, Schunemann HJ, Fonseca J, et al. MACVIA-ARIA Sentinel Network for allergic rhinitis (MASK-rhinitis): the new generation guideline implementation. Allergy 2015; 70: 1372-92.

44. Muraro A, Werfel T, Hoffmann-Sommergruber K, et al. EAACI food allergy and anaphylaxis guidelines: diagnosis and management of food allergy. Allergy 2014; 69: 1008-25.

45. The International Study of Asthma and Allergies in Children (ISAAC) Steering Committee Worldwide variation in prevalence of symptoms of asthma, allergic rhinoconjunctivitis, and atopic eczema: ISAAC. Lancet 1998; 351: 1225-32.

46. Levine A, Griffiths A, Markowitz J, et al. Pediatric modification of the Montreal classification of inflammatory bowel disease: the Paris classification. Inflamm Bowel Dis 2011; 17: 1314-21.

47. Glassman M, Newman L, Berezin S, et al. Cow's milk protein sensitivity during infancy in patient with inflammatory bowel disease. Am J Gastr 1990; 85: 838-40.

48. Imanzadeh F, Nasri P, Sadeghi S, et al. Food allergy among Iranian children with inflammatory bowel disease: a preliminary report. J Res Med Sci 2015; 20: 855-9.

49. Heine R. Gastrointestinal food allergies. Chem Immunol Allergy 2015; 101: 171-80.

50. Savage J, Johns C. Food allergy: epidemiology and natura history. Immunol Allergy Clin N Am 2015; 35: 45-59.

51. Dadas-Stasiak E, Kalicki B, Jung A. Najczęściej występujące przyczyny i rodzaje alergii u dzieci w świetle aktualnej epidemiologii. Pediatr Med Rodz 2010; 6: 92-9.

52. Myrelid P, Dufmats M, Lilja I, et al. Atopic manifestations are more common in patients with Crohn disease than in the general population. Scand J Gastroenterol 2004; 39: 731-6.

53. Kuenzig M, Barnabe C, Seow C. Asthma is associated with subsequent development of inflammatory bowel disease: a population-based case-control study. Clin Gastroenterol Hepatol 2017; 15: 1405-12.

54. Kanazawa H, Yoshikawa J. A case-control study of bronchia asthma associated with ulcerative colitis: role of airway microvascular permeability. Clin Exp Allergy 2005; 35: 1432-6.

55. Peng Y, Liao W, Su C, et al. Association of inflammatory bowel disease with asthma risk: a nationwide cohort study. Allergy Asthma Proc 2015; 36: 92-8.

56. Kappelman M, Galanko J, Porter C, et al. Association of paediatric inflammatory bowel disease with other immunemediated diseases. Arch Dis Child 2011; 96: 1042-6. 
57. Hammer B, Ashurst P, Naish J. Diseases associated with ulcerative colitis and Crohn's disease. Gut 1968; 9: 17-21.

58. Roberts D, Rhodes J, Heatley R, et al. Atopic features in ulcerative colitis. Lancet 1978; 1: 1262.

59. Keil T, Bockelbrink A, Reich A, et al. The natural history of allergic rhinitis in childhood. Pediatr Allergy Immunol 2010; 21: 962-9. 